$\$=$

\title{
Assessment of extra pulmonary tuberculosis (EPTB) cases from selected tuberculosis units (TUs) of Himachal Pradesh, India
}

\author{
Ashok Kumar Bhardwaj ${ }^{1}$, Dinesh Kumar ${ }^{2 *}$, Sunil Kumar Raina ${ }^{3}$, Sushant Sharma ${ }^{4}$, Vishav Chander ${ }^{2}$ \\ ${ }^{1}$ Professor \& Head Department of Community Medicine, Dr. Rajendra Prasad Government Medical College, Kangra, \\ Himachal Pradesh, India. 176001 \\ ${ }^{2}$ Assistant Professor Department of Community Medicine, Dr. Rajendra Prasad Government Medical College, Kangra, \\ Himachal Pradesh, India. 176001 \\ ${ }^{3}$ Associate Professor Department of Community Medicine, Dr. Rajendra Prasad Government Medical College, Kangra, \\ Himachal Pradesh, India. 176001 \\ ${ }^{4}$ Lecturer of Bio-statistics Department of Community Medicine, Dr. Rajendra Prasad Government Medical College, Kangra, \\ Himachal Pradesh, India. 176001 \\ *Corresponding author E-mail: dinesh9809@gmail.com
}

\begin{abstract}
Introduction: Extra-Pulmonary Tuberculosis (EPTB) gained attention for study its local disease epidemiology for disease control. Objective: To study the distribution and determinants of EPTB in randomly selected tuberculosis units (TUs) of Himachal Pradesh. Methodology: Multistage random sampling was used; four districts were selected randomly from total 12 districts of state and then one TU was selected from each selected district. In addition, two medical colleges were also included as a referral point for EPTB cases.

Results: Total 463 EPTB cases were studied during one-year study period; pleural (41.9\%) and Lymph Node (31.3\%) was frequently observed involved sites. Among male's pleural effusion (48.2\%) was commonly involved site followed by lymph node (23.5\%), whereas, lymph node was involved in $40.6 \%$ followed by pleural effusion in $34.4 \%$ females. Other common sites for EPTB were abdomen (6.0\%), bone (5.6\%), meninges (5.2\%) and pericardium (3.9\%) and for both males and females. Mean duration of diagnosis since appearance of symptoms was 40 days; only $10.0 \%$ of patients received antibiotics for the average of two weeks before formulating EPTB diagnosis. About $35.0 \%$ patients underwent FNAC (Fine Needle Aspiration Cytology) to establish diagnosis.

Conclusion: Invasive diagnostic facilities at peripheral health institutions will help further to better understand EPTB epidemiology.
\end{abstract}

Keywords: Burden, Extra-Pulmonary Tuberculosis, Tuberculosis Unit.

\section{Introduction}

Annually, Tuberculosis (TB) affects 9.4 million individuals and cause 1.3 million deaths worldwide. Mycobacterium tuberculosis bacilli has infected nearly one third of the world's population, and of these approximately $10 \%$ of them have a lifetime risk of developing TB disease (WHO Report 2010). Though pulmonary form of TB is common form and focused on disease control program, but Extra Pulmonary Tuberculosis (EPTB) estimated to contribute $15-20 \%$ of total TB cases (Arora VK 2006). It observed to be more common in individuals with a compromised immune status like in HIV and under-nutrition along with in females and nonethnic groups (Cruz AT 2010, Sharma SK 2004, Peto HM 2009). Due to its non-communicable nature, less attention was paid for its control. A growing argument further suggested that the underreporting of EPTB was due to lack of clinical suspicion and diagnostic algorithm. Evidence from India across 16 sampled districts found that almost half of EPTB cases were diagnosed only on clinical grounds with Montoux as a commonly available diagnostic test (Sharma SK 2004, Sreeramareddy TC 2008, Wares F 2005, Jamil B 2008). Studied EPTB epidemiology observed that the affected sites in a human body varies according to geography and population. (Makaju R 2010, Igazali A 2004, Fiske CT 2010).
Available information revealed that the most common sites of EPTB was lymph node followed by pleura and abdomen (Sreeramareddy TC 2008, Makaju R 2010, Shanmuganathan A 2013, Sharma SK 2005). Though, some studies observed genitorurinary and skin as common affected sites as well (Sreeramareddy TC 2008, Chandir S 2010, Arora VK 1995, Gupta SN 2011). EPTB observed to affect the population of economically productive age group of 15 to 35 years than extremes of age (Sreeramareddy TC 2008, Makaju R 2010, Chandir S 2010, Shanmuganathan A 2013). It can occur as an isolated form or along with pulmonary form of TB and also can affect multiple organs at one point of time. Present as the co-morbid form with pulmonary TB, EPTB patients have high probability of death within six months of diagnosis (Sharma SK 2005, Swaminathan S 2000). Studies reported that the pulmonary involvement ranges from $20.0 \%$ to $50.0 \%$ in EPTB cases (Shanmuganathan A 2013, Malek M 2012, Parimon T 2008). In resource limited countries with lack of diagnostic facilities, identification of EPTB cases relies significantly on high index of clinical suspicion. For India, Revised National Tuberculosis Control Program (RNTCP) is a successful and nationwide program, which showed a gradual reduction in disease transmission and a control of pulmonary TB.20 Concurrent evidence have observed a rising proportion of EPTB 
with simultaneous reduction in PTB cases (Igazali A 2004, Shanmuganathan A 2013, Sharma SK 2005, Arora VK 1995). Available infrastructure in RNTCP helps to understand local disease epidemiology and will augment the disease control efforts. With this background, the present study was carried out with the availability and accessibility of RNTCP to understand the EPTB burden in state of Himachal Pradesh.

\section{Methodology}

A cross-sectional study was carried out to study EPTB cases from two medical colleges and four additional randomly selected Tuberculosis Units (TUs) of Himachal Pradesh catering a total population of $6,16,000$ (about $10.0 \%$ of state population). In a studied state, the medical colleges catered all referred cases of EPTB from peripheral health institutions across the state. All studied TUs were selected using multistage random sampling method. In the first stage, from a list of total 12 districts of state, four districts were selected randomly by lottery method. Then in the second stage, randomly, one TU from each of the selected district was selected. Purposefully, two medical colleges of the state were included as TUs as both were reporting maximum of EPTB cases. Both medical colleges along with selected TUs catered upper and lower areas of Himachal Pradesh and are geographically representative of entire state. After obtaining informed consent, trained interviewers collected information from EPTB patients of more than 18 years of age at the TU settings using structured pre-tested interviewer administered questionnaire. All the registered case switched over to non-DOTS treatment, transferred in and transferred out patients during the study period and patients completed treatment at the time of start of study were excluded from study. EpiInfo software (version 7) for windows was used for data entry and analysis. Before its commencement, the study got ethical clearance from the Institute ethical committee (IEC).

\section{Results}

The observed mean age was 36.9 and 33.6 year $(\mathrm{p}=0.00)$ for male and female respectively. And $61.5 \%$ of the patients were less than 35 years of age. When assessed further more females observed of less than 35 years of age, whereas, most males were of more than 35 years. (Table: 1) Among all cases of EPTB, both pleural (41.9\%) and Lymph Node (31.3\%) was commonly involved sites in $73.2 \%$ of patients. Pleural involvement was frequent in patients of more than $65(53.6 \%)$ year followed by $20-35(44.8 \%), 51-65$
(36.7\%), and 36-50 (33.0\%) year age groups. Age group distribution for lymph node involvement observed similar for patients of $20-35(34.3 \%), 36-50(35.0 \%)$ and $>65(21.4 \%)$ year of age. Apart from lymph node and pleural involvement- though less in the number patients from 51 to 65 year of age were observed commonly with bone $(14.2 \%)$, abdominal $(10.2 \%)$, pericardium $(8.2 \%)$, and meningeal $(6.1 \%)$ form of EPTB. Except meningeal form, the other form of EPTB was observed common for patients of more than 65 years of age.

Dominantly, pleural and lymph node was involved in both males and females. Among male's pleural effusion (48.2\%) was commonly involved site followed by lymph node (23.5\%), whereas, lymph node was involved in $40.6 \%$ followed by pleural effusion in $34.4 \%$ females. Among males, pleural effusion observed mostly among 20 to $35(54.5 \%)$ followed by $>65$ years $(47.1 \%)$ of age. Overall and both in males and females, following pleural and lymph node, other common sites for EPTB were abdomen $(6.0 \%)$, bone $(5.6 \%)$, meninges $(5.2 \%)$ and pericardium $(3.9 \%)$. In a descending order, these sites were commonly observed in EPTB cases with 20-35, 36-50, and 51-65 year of age. (Table: 2). those diagnosed for EPTB, $440(94.2 \%)$ of patients were started for category-I, and rest were on category-III treatment.

Among cases of EPTB, the mean interval between appearance of symptoms and diagnosis was 38.5 day (SD: 44.7; Median: 29.0; IQR: 14.0-55.0). There were average 3.1 (SD: 1.9; median: 3; IQR: 2.0-4.5) medical consultations before establishment of diagnosis for EPTB. Total $272(57.6 \%)$ patients were diagnosed by medical specialist and $190(40.2 \%)$ by the general physician. Sputum smear was examined only in $31.3 \%$ of patients, and of that sputum was examined sputum was collected twice (as per RNTCP protocol) in $78(17.7 \%)$ patients.

As an isolated symptom, fever was reported among $52(20.5 \%)$ and general weakness in $18(7.1 \%)$ cases. Whereas, it was commonly observed along with cough, weight loss, chest pain, and loss of appetite. Total 22 cases reported history of swelling in the neck region associated with pain. In the present study, as pleural and lymph node TB was the common form of EPTB, swelling alone was reported in $68.5 \%$ and swelling with fever in $7.3 \%$ patients. Among patients with lymph node TB, fever alone was reported symptom in $18.5 \%$ and fever along with loss of appetite in $2.4 \%$ of patients. Whereas, among patients with pleural effusion, the most common symptom was chest pain $(37.5 \%)$ and fever $(18.5 \%)$. Fever associated with chest pain was observed in $7.8 \%$ and fever with loss of appetite was found in $5.5 \%$ patients with pleural effusion. (Figure: 1)

Table 1: Age Group Distribution of Extra-Pulmonary Tuberculosis (EPTB) Cases in Selected Tuberculosis Units of Himachal Pradesh, 2013.

\begin{tabular}{|c|c|c|c|c|}
\hline $\begin{array}{l}\text { Age Group } \\
\text { (years) }\end{array}$ & $\begin{array}{l}\text { Male } \\
\mathrm{N}(\%)\end{array}$ & $\begin{array}{l}\text { Female } \\
\mathrm{N}(\%)\end{array}$ & $\begin{array}{l}\text { Total } \\
\mathrm{N}(\%)\end{array}$ & $\mathrm{X}^{2}, \mathrm{p}$ value \\
\hline$<35$ & $143(56.9)$ & $143(67.4)$ & $286(61.7)$ & $3.3,0.06$ \\
\hline $36-50$ & $63(25.1)$ & $37(17.5)$ & $100(21.6)$ & $1.2,0.27$ \\
\hline$>65$ & $17(6.8)$ & $11(5.2)$ & $28(6.1)$ & $0.6,0.41$ \\
\hline Total & $251(100.0)$ & $212(100.0)$ & $463(100.0)$ & - \\
\hline
\end{tabular}

Table 2: Age and Gender Distribution According To Site of Involvement of Extra-Pulmonary Tuberculosis (EPTB) Cases in Selected Tuberculosis Units of Himachal Pradesh, 2013.

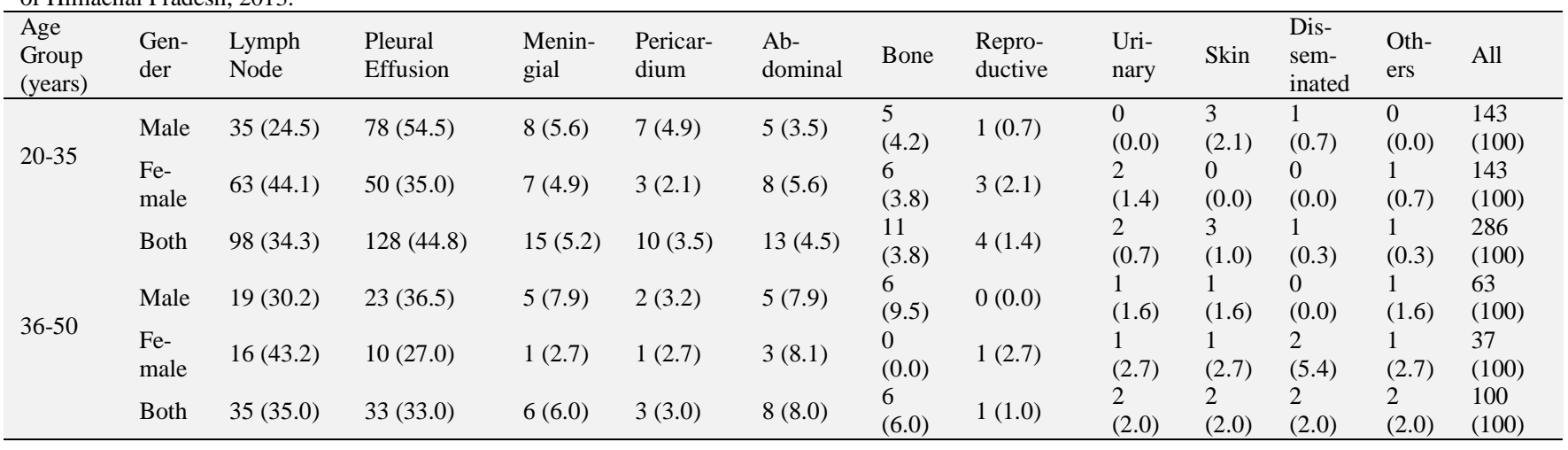




\begin{tabular}{|c|c|c|c|c|c|c|c|c|c|c|c|c|c|}
\hline \multirow{2}{*}{$51-65$} & Male & $2(7.1)$ & $12(42.9)$ & $2(7.1)$ & $3(10.7)$ & $3(10.7)$ & $\begin{array}{l}3 \\
(10.7)\end{array}$ & $0(0.0)$ & $\begin{array}{l}1 \\
(3.6)\end{array}$ & $\begin{array}{l}0 \\
(0.0)\end{array}$ & $\begin{array}{l}1 \\
(3.6)\end{array}$ & $\begin{array}{l}1 \\
(3.6)\end{array}$ & $\begin{array}{l}28 \\
(100)\end{array}$ \\
\hline & $\begin{array}{l}\mathrm{Fe}- \\
\text { male }\end{array}$ & $4(19.0)$ & $6(28.6)$ & $1(4.8)$ & $1(4.8)$ & $2(9.5)$ & $\begin{array}{l}4 \\
(19.0)\end{array}$ & $0(0.0)$ & $\begin{array}{l}1 \\
(4.8)\end{array}$ & $\begin{array}{l}1 \\
(4.8)\end{array}$ & $\begin{array}{l}1 \\
(4.8)\end{array}$ & $\begin{array}{l}0 \\
(0.0)\end{array}$ & $\begin{array}{l}21 \\
(100)\end{array}$ \\
\hline \multirow{4}{*}{$>65$} & Both & $6(12.2)$ & $18(36.7)$ & $3(6.1)$ & $4(8.2)$ & $5(10.2)$ & $\begin{array}{l}7 \\
(14.3)\end{array}$ & $0(0.0)$ & $\begin{array}{l}2 \\
(4.1)\end{array}$ & $\begin{array}{l}1 \\
(2.0)\end{array}$ & $\begin{array}{l}2 \\
(4.1)\end{array}$ & $\begin{array}{l}1 \\
(2.0)\end{array}$ & $\begin{array}{l}49 \\
(100)\end{array}$ \\
\hline & Male & 3 (17.6) & $8(47.1)$ & $0(0.0)$ & $1(5.9)$ & $1(5.9)$ & $\begin{array}{l}2 \\
(11.8)\end{array}$ & $0(0.0)$ & $\begin{array}{l}1 \\
(5.9)\end{array}$ & $\begin{array}{l}0 \\
(0.0)\end{array}$ & $\begin{array}{l}0 \\
(0.0)\end{array}$ & $\begin{array}{l}1 \\
(5.9)\end{array}$ & $\begin{array}{l}17 \\
(100)\end{array}$ \\
\hline & $\begin{array}{l}\mathrm{Fe}- \\
\text { male }\end{array}$ & $3(27.3)$ & 7 (63.6) & $0(0.0)$ & $0(0.0)$ & $1(9.1)$ & $\begin{array}{l}0 \\
(0.0)\end{array}$ & $0(0.0)$ & $\begin{array}{l}0 \\
(0.0)\end{array}$ & $\begin{array}{l}0 \\
(0.0)\end{array}$ & $\begin{array}{l}0 \\
(0.0)\end{array}$ & $\begin{array}{l}0 \\
(0.0)\end{array}$ & $\begin{array}{l}11 \\
(100)\end{array}$ \\
\hline & Both & $6(21.4)$ & $15(53.0)$ & $0(0.0)$ & 1 (3.6) & $2(7.1)$ & $\begin{array}{l}2 \\
(7.1)\end{array}$ & $0(0.0)$ & $\begin{array}{l}1 \\
(3.6)\end{array}$ & $\begin{array}{l}0 \\
(3.6)\end{array}$ & $\begin{array}{l}0 \\
(0.0)\end{array}$ & $\begin{array}{l}1 \\
(3.6)\end{array}$ & $\begin{array}{l}28 \\
(100)\end{array}$ \\
\hline \multirow[t]{2}{*}{ All } & Male & $59(23.5)$ & $121(48.2)$ & $15(6.0)$ & $13(5.2)$ & $14(5.6)$ & $\begin{array}{l}16 \\
(6.4)\end{array}$ & $1(0.4)$ & $\begin{array}{l}3 \\
(1.2)\end{array}$ & $\begin{array}{l}4 \\
(1.6)\end{array}$ & $\begin{array}{l}2 \\
(0.8)\end{array}$ & $\begin{array}{l}3 \\
(1.2)\end{array}$ & $\begin{array}{l}251 \\
(100)\end{array}$ \\
\hline & $\begin{array}{l}\text { Fe- } \\
\text { male }\end{array}$ & $86(40.6)$ & $73(34.4)$ & $9(4.2)$ & $5(2.4)$ & $14(6.6)$ & $\begin{array}{l}10 \\
(4.7)\end{array}$ & 4 (1.9) & $\begin{array}{l}4 \\
(1.9)\end{array}$ & $\begin{array}{l}2 \\
(0.9)\end{array}$ & $\begin{array}{l}3 \\
(1.4)\end{array}$ & $\begin{array}{l}2 \\
(0.9)\end{array}$ & $\begin{array}{l}212 \\
(100)\end{array}$ \\
\hline All & Both & $\begin{array}{l}145 \\
(31.3)\end{array}$ & $194(41.9)$ & $24(5.2)$ & $18(3.9)$ & $28(6.0)$ & $\begin{array}{l}26 \\
(5.6) \\
\end{array}$ & $5(1.1)$ & $\begin{array}{l}7 \\
(1.5) \\
\end{array}$ & $\begin{array}{l}6 \\
(1.3) \\
\end{array}$ & $\begin{array}{l}5 \\
(1.1) \\
\end{array}$ & $\begin{array}{l}5 \\
(1.1) \\
\end{array}$ & $\begin{array}{l}463(10 \\
0)\end{array}$ \\
\hline
\end{tabular}

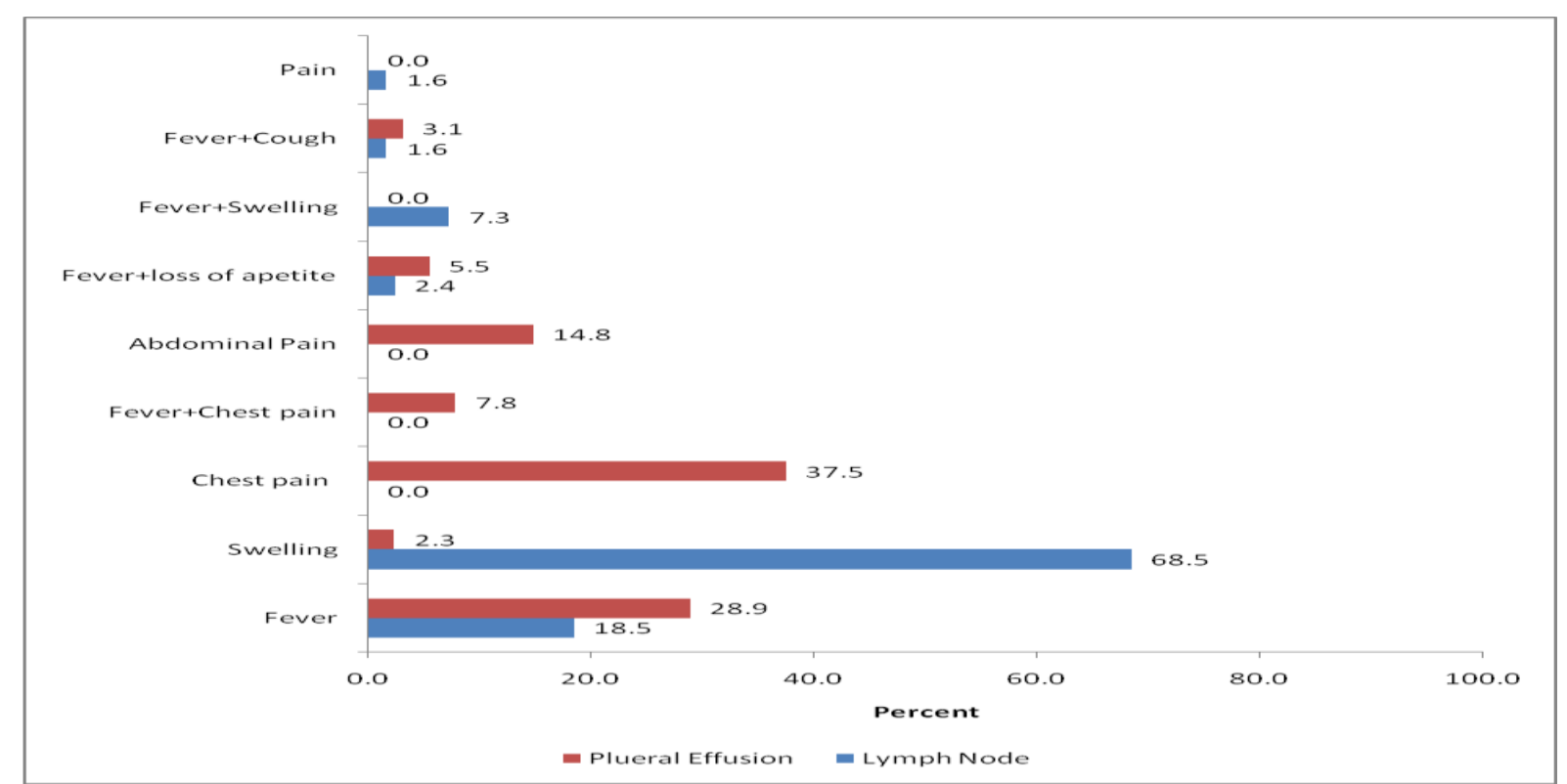

Fig. 1: Symptomology for Lymph Node TB (LNTB) and Pleural Effusion in Selected Tuberculosis Units of Himachal Pradesh, 2013.

Table 3: Distribution of Substance Abuse among EPTB Patients Specifically for Lymph Node and Pleural Effusion in Selected Tuberculosis Units of Himachal Pradesh, 2013.

\begin{tabular}{llll}
\hline Substance abuse & Status & $\begin{array}{l}\text { Lymph Node } \\
144(\%)\end{array}$ & $\begin{array}{l}\text { Pleural Effusion } \\
191(\%)\end{array}$ \\
\hline \multirow{3}{*}{ Alcohol } & Never consumed & $109(81.3)$ & $135(72.6)$ \\
& Currently consuming & $14(10.4)$ & $32(17.2)$ \\
& Quitted & $11(8.2)$ & $19(10.2)$ \\
Smoking & Never & $122(84.7)$ & $143(74.9)$ \\
& Current smoker & $11(7.6)$ & $31(16.2)$ \\
& Quitted & $11(7.6)$ & $11(9.8)$ \\
\end{tabular}

Medication apart from DOTS (Directly Observed Treatment Short Course), only 50 (10.5\%) patients were prescribed for any form of antibiotics prior to diagnosis for EPTB. Of these, 36.0\% were prescribed for cephalosporins, $30.0 \%$ for amoxicillin, and rest for azithromycin and fluoroquinolones. The antibiotics were prescribed for an average duration of 14.2 day.

For establishing EPTB diagnosis, X-ray was done in total 106 $(22.3 \%)$ patients and specifically chest $x$-ray in $45(42.4 \%)$ patients. Total $37(7.8 \%)$ and $16(3.3 \%)$ patients were assessed with Computerized Tomography (CT) scan and Magnetic Resonance Imaging (MRI). As a routine, Montoux test was done among 66 $(15.5 \%)$ of patients and was positive among $5(7.5 \%)$ patients. FNAC was done in total 158 patients and assessed for ADA, it was observed positive among $22(13.9 \%)$ patients with mean level of $84.5 \mathrm{U} / \mathrm{L}$. Total 122 patients $(77.2 \%)$ were declared positive as per FNAC assessment. FNAC was mostly $(77.2 \%)$ carried out to assess lymph node followed by pleural (21.5\%) and abdominal (6.3\%) TB. Total 35 and 4 patients had diagnostic reports for pleural and abdominal fluid respectively. Pleural fluid was observed to be yellowish in color in $11(31.4 \%)$ tested samples with mean level of ADA as 79.3 U/L. Biologic medical specimens were microbiologically cultured for TB only for eight patients.

\section{Discussion}

In the state of Himachal Pradesh, Extra-pulmonary tuberculosis (EPTB) remains un-discussed as a significant public health issue due to limited evidence. We have assessed EPTB burden in selected TUs and observed that EPTB can be diagnosed better with good diagnostic facilities, as most of cases were from medical colleges. Lymph node and Pleural effusion were observed as a common extra-pulmonary form of TB in about $70.0 \%$ of cases. Among males lymph node and among females pleural effusion was frequently observed site of involvement. Under RNTCP, EPTB diagnosis primarily based on excluding its pulmonary form, whereas, assessment for definitive diagnosis an invasive test to acquire tissue specimen with culture facility is required. Current study observed that in $34.3 \%$ patients FNAC was carried out to collect specimen and that too were carried out in medical colleges. 
Pulmonary form of TB being the commonest type and been targeted for disease control due to its communicable nature. Apart from lung parenchyma involvement, Mycobacterium tuberculosis can infest and affect every organ of the body that refers as EPTB. It often affects an economically productive age group, whereas extremes of age comparatively less affected. In a European Union study, it was observed that about $50.0 \%$ of EPTB cases belonged to 15 to 44 year age group (Shanmuganathan A 2013, Sandgren A 2013, Prakasha SR 2013) Various other studies reported that average age of EPTB patients was from 25 to 45 year (Ilgazli A 2004, Chandir S 2010, Kruijshaar ME 2009, El-Hazmi MM 2012, Leeds IL 2012). Present study also observed that more of patients were of productive age as the mean age for males and females was 36.9 and 33.6 year $(\mathrm{p}=0.00)$ respectively, and most $(46.8 \%)$ of patients belonged to 20 to 35 year age group. Gender predisposition observed mixed response as in some studies more of females were involved (Parimon T 2008, García-Rodríguez JF 2011) and in other, males were found to be commonly affected (Ilgazli A 2004, Prakasha SR 2013). 10, 21-25 in the present study almost half (56.9\%) of the affected patients were males.

Patients with EPTB may manifest with constitutional symptoms such as fever, anorexia, weight loss, malaise and fatigue. In India with limited practice of diagnostic facilities and with obscure location of EPTB site, patient often presents with pyrexia of unknown origin (PUO) or signs and symptoms related to organ functional impairment. In present study, fever was reported as an isolated symptom in $20.5 \%$ of cases and in about two thirds of cases, it was commonly observed with cough, weight loss, chest pain, and loss of appetite.

Evidence observed EPTB as a common disease entity, as a time trend in Spain showed a $27.0 \%$ increase in lymphatic site involvement from 1991-1996 to $37.6 \%$ in 2003-2008.26 Lymph node and lung pleura observed to be commonly affected site presenting with swelling and fever. Some evidence observed lymph node as first common site (Sharma SK 2004, Sreeramareddy TC 2008) and some supported pleural (Prakasha SR 2013, Piryani RM 2008) involvement as the most common type of EPTB. In the present study in about seventy percent of cases, pleura $(41.9 \%)$ and lymph node $(31.2 \%)$ was found to be commonly involved Abdominal, meningeal, pericardial and spinal was next commonly infested sites for TB. (Figure: 1)

Demonstration of Mycobacterium tuberculosis by microbiological, cytopathological or histopathological method is a definitive form of diagnosis as clinical presentation of EPTB is usually atypical. So, it becomes vital to isolate tissue/body fluid for analysis by carrying out invasive methods. Pathological finding mostly suggests a "granulomatous infection" indicative of other differential diagnoses rather than definitive tuberculosis. Therefore, treating physician more often relies upon clinical impression, radiological and endoscopic appearances, and non-conventional diagnostic methods to diagnose EPTB. Lymph node is commonly accessible site for excision and diagnosis (Sharma SK 2004). In a case of lymph node tuberculosis, FNAC and excision biopsy of the most accessible peripheral lymph node confirms diagnosis most of the times. In the present study, FNAC was done in 123 patients, in which ADA was positive among $22(17.9 \%)$ of patients with mean level of $84.5 \mathrm{U} / \mathrm{L}$. Total 122 patients $(25.7 \%)$ were declared tuberculosis positive as per the reports of FNAC.

Similarly, cerebrospinal fluid (CSF) and ascitic fluid examination provide a diagnostic clue in patients with neurological and peritoneal tuberculosis respectively. Sampled pleural fluid from EPTB patients is typically clear or straw coloured, but cloudy or serosanguinous fluid could also be obtained. In present study, pleural fluid was collected from 35 and abdominal fluid from four symptomatic patients. Pleural fluid was observed to be yellowish in color in $11(31.4 \%)$ tested samples. ADA and protein assessment was available for 6 patients only with mean of $79.3 \mathrm{U} / \mathrm{L}$ and 5.0 respectively. Whereas, specimens were microbiologically cultured for TB in only eight patients.

Diagnosis for EPTB based on Tuberculin test alone is insufficient in countries like India where TB is highly endemic. Review for various forms of EPTB showed tuberculin positivity of $74-80 \%$ for lymph node TB, $73-93 \%$ for pleural effusion, $58-100 \%$ for abdominal TB, $75-100 \%$ for pericardial TB, $67.0 \%$ for cutaneous TB, and $21-62 \%$ for disseminated and milliary TB (Sharma SK 2004). Being an adjunctive test, in present study, Montoux was done only in $66(15.5 \%)$ patients and was positive in five $(7.5 \%)$ patients.

With the widespread availability of CT and MRI scan, localization and excision of tissue of EPTB site can be better accessible and carried out easily. CT scan is found to be helpful in localizing intrathoracic and intraabdominal lymphadenopathy and radiologically guided FNAC and biopsy (Sharma SK 2004). In present study, total $37(7.8 \%)$ and $16(3.3 \%)$ patients were assessed with Computerized Tomography (CT) scan and Magnetic Resonance Imaging (MRI). No information was available for collection of tissue sample for the diagnosis of EPTB using CT/MRI.

With the inaccessible nature of EPTB sites along with lack of diagnostic facilities and skills to access and isolate tissue/fluid, most cases remain undiagnosed and late if diagnosed. In the present study almost all (97.0\%) were put into category-I treatment with delay in diagnosis with an average of 40 days along with an average of three medical consultations. As most patients were on category-I i.e., severally ill, and $10.0 \%$ of those were prescribed with another form of antibiotics mostly cephalosporins and amoxicillin for an average of two weeks.

Tuberculosis control focus on early detection and treatment of pulmonary form of tuberculosis but EPTB contributes to around 15 to 20 percent of all TB cases in India as compare to $25.0 \%$ in France and 50.0\% in Canada (Sudre P 1996, Stelianides S 1997). Tuberculosis (both PTB and EPTB) found to be co-existent with HIV and recognized as an AIDS defining disease (Pitchenik AE 1984). Atypical clinical presentation of EPTB usually simulates to inflammatory and neoplastic conditions resulted in delayed diagnosis and treatment. Diagnosis of EPTB requires a skilled work force for carrying out invasive diagnostic procedures along with good clinical judgment. RNTCP as a largest and successful program in the country has achieved and sustained its objectives of case detection ( $73 \%$ against the objective of $74 \%$ ) and treatment success rate ( $88 \%$ against the objective of $>85 \%$ ) amongst new smear-positive TB cases. It has been achieved through more than 13,000 Designated Microscopy Centers (DMCs) and about 4, 00,000 directly Observed Treatment (DOT) services providers throughout the country (TB India 2013). Therefore, presence of such a vast diagnostic and treatment infrastructure for tuberculosis control provides an opportunity for capacity building to make EPTB diagnosis and treatment. Enabled with skills for EPTB diagnosis and treatment health care professionals can suspect and send the pathological tissue/fluid to established 31 Culture and Drug Susceptibility Testing laboratories (11 of them have Line Probe Assay) for diagnosis. Once diagnosis is made the patient can be then referred back at DOTS centre for treatment of EPTB. This approach certainly will strengthen the program with the involvement of medical colleges, which reported maximum number of EPTB cases. Previous study in the same state reflected early case detection and low default rate among sputum smear positive cases, therefore, asking to shift focus to EPTB to reduce disease burden in state (Bhardwaj AK 2014).

While concluding, it can be stated that EPTB possesses significant share for Tuberculosis burden in state, but unmeasured. In primary health care settings, the diagnosis is difficult and mostly based upon signs and symptoms, and excluding pulmonary form of diagnosis, whereas, in medical colleges, availability of good diagnostic facilities helps clinicians to confirm EPTB. As most of the cases in primary health care setting remain missing due to lack of diagnostic facilities, specimen can be collected at peripheral health facility with the availability of medical officer and sent to medical college for testing. Such significant involvement of medical colleges under RNTCP is recommended to ascertain actual burden of EPTB in a population. 


\section{Conflict of interest}

None

\section{Acknowledgement}

We express our sincere thanks to "Disha Jan hit Samiti" (a NonGovernmental Organization) for their valuable contribution towards data collection.

\section{References}

[1] Report. Geneva: WHO; World Health Organization. Global tuberculosis control 2010. Available at: http://www.who.int/tb/publications/global_report/2010/en/. Accessed June 282014.

[2] Arora VK, Gowrinath K, Rao RS (1995) Extrapulmonary involvement in HIV with special reference to tuberculosis cases. Ind J Tub 42, 27.

[3] Arora VK, Gupra R (2006) Trends of extrapulmonary tuberculosis under revised national tuberculosis control programme: A study from south Delhi. Indian J Tuberc 53, 77.

[4] Bhardwaj AK, Kashyap S, Bansal P, Kumar D, Raina SK, Chander V, Sharma S. (2014) Factors Influencing Early Health Facility Contact and Low Default Rate among New Sputum Smear Positive Tuberculosis Patients, India. Pulmonary Medicine http://dx.doi.org/10.1155/2014/132047.

[5] Cruz AT, Starke JR (2010) Pediatric tuberculosis. Pediatr Rev 31(1), 13-25. http://dx.doi.org/10.1542/pir.31-1-13.

[6] Chandir S, Hussain H, Salahuddin N, Amir M, Ali F, et al (2010) Extrapulmonary tuberculosis: a retrospective review of 194 cases at a tertiary care hospital in Karachi, Pakistan. J Pak Med Assoc 60, 105.

[7] El-Hazmi MM, Al-Otaibi FE (2012) Predictors of pulmonary involvement in patients with extra-pulmonary tuberculosis. J Family Community Med 19, 88-92. http://dx.doi.org/10.4103/22308229.98287.

[8] Fiske CT, Griffn MR, Erin H, Warkentin J, Lisa K, Arbogast PG, Sterling TR (2010) Black race, sex, and extrapulmonary tuberculosis risk: an observational study. BMC Infect Dis 10, 16 http://dx.doi.org/10.1186/1471-2334-10-16

[9] García-Rodríguez JF, Álvarez-Díaz H, Lorenzo-García MV, MariñoCallejo A, Fernández-Rial Á, Sesma-Sánchez P (2011) Extrapulmonary tuberculosis: epidemiology and risk factors. Enferm Infecc Mi$\begin{array}{lll}\text { crobiol Clin } & \text { 29(7), } & \text { 502-9. }\end{array}$ http://dx.doi.org/10.1016/j.eimc.2011.03.005.

[10] Gupta SN, Gupta N (2011) Evaluation of revised national tuberculosis control program, district Kangra, Himachal Pradesh, India, 2007. Lung India 28, 163-8. http://dx.doi.org/10.4103/0970-2113.83970.

[11]Ilgazli A, Boyaci H, Basyigit I, Yildiz F (2004) Extra-pulmonary tuberculosis; clinical and epidemiological spectrum of 636 cases. Arch Med Res 35, 435-41. http://dx.doi.org/10.1016/j.arcmed.2004.05.008.

[12] Jamil B, Qamruddin S, Sarwari AR, Hasan R (2008) an assessment of mantoux tests in the diagnosis of tuberculosis in a BCG-vaccinated, tuberculosis endemic area. Journal of Infectious Diseases 17(1), 1822.

[13]Kruijshaar ME, Abubakar I (2009) Increase in extrapulmonary tuberculosis in England and Wales 1999-2006. Thorax 64, 10905. http://dx.doi.org/10.1136/thx.2009.118133.

[14]Leeds IL, Magee MJ, Kurbatova EV, del Rio C, Blumberg HM, Leonard MK, Kraft CS (2012) Site of extrapulmonary tuberculosis is associated with HIV infection. Clin Infect Dis 55, 75-81. http://dx.doi.org/10.1093/cid/cis303.

[15]Makaju R, Mohammad A, Thakur NK (2010) Scenario of Extrapulmonary tuberculosis in Tertiary care center. J Nepal Health research council 16, 48-50.

[16]Malek M, El Hazmi, Fawzia E Al Otaibi (2012) Predictors of Pulmonary involvement in patients with extrapulmonary Tuberculosis. $J$ Family Community Medicine 19, 88-92. http://dx.doi.org/10.4103/2230-8229.98287.

[17]Parimon T, Spitters CE, Muangaman N, Evathrongchit J, et al (2008) Unexpected pulmonary involvement in extrapulmonary TB patients. Chest 134, 589-94. http://dx.doi.org/10.1378/chest.08-0319.

[18]Prakasha SR, Suresh G, D'sa IP, Shetty SS, Kumar SG (2013) Mapping the pattern and trends of extrapulmonary tuberculosis. J Glob Infect Dis 5(2), 54-9. http://dx.doi.org/10.4103/0974-777X.112277.

[19]Peto HM, Pratt RH, Harrington TA, LoBue PA, Armstrong LR (2009) Epidemiology of extrapulmonary tuberculosis in the United States,
1993-2006. Clin Infect Dis 49(9), 1350-7. http://dx.doi.org/10.1086/605559.

[20]Piryani RM, Kohli SC, Shrestha G, Rawat T (2008) Tuberculosis diagnosed / managed at NGMC, Teaching Hospital, Kohalpur: A joint private-public effort. Kathmandu Univ Med J (KUMJ) 6(21), 2832.

[21]Pitchenik AE, Cole C, Russell BW, et al (1984) Tuberculosis, atypical mycobacteriosis and acquired immunodeficiency syndrome among Haitian and non-Haitian patients in south Florida. Ann Intern Med 101, 641-5. http://dx.doi.org/10.7326/0003-4819-101-5-641.

[22]Sandgren A, Hollo V, van der Werf MJ (2013) Extrapulmonary tuberculosis in the European Union and European Economic Area, 2002 to 2011. Euro Surveill 18(12), 1-9.

[23] Sharma SK, Mohan A (2004) Extrapulmonary tuberculosis. Indian J Med Res 120(4), 316-53.

[24] Sharma SK, Mohan A, Kadhiravan T (2005) HIV-TB co-infection; epidemiology, diagnosis and management. Indian J Med Res 550-67.

[25] Shanmuganathan A, Srinivasan R, Thilgavathy G, Satishkumar D, Sidduraj C, James B (2013) Determination of Sites Involved, HIV Co-Infection \& Utility of Diagnostic Modalities in EPTB. J Clin Diagn Res 1644-46. http://dx.doi.org/10.7860/jcdr/2013/6363.3301.

[26]Sreeramareddy TC, Panduru VK, Verma SC, Joshi HS, Bates MN (2008) Comparison of pulmonary and extrapulmonary tuberculosis in Nepal - a hospital based retrospective study. BMC Infect Dis 8. http://dx.doi.org/10.1186/1471-2334-8-8.

[27] Stelianides S, Belmatoug N, Fantin B (1997) Manifestations and diagnosis of extrapulmonary tuberculosis. Rev Mal Respir 14L, S72-87.

[28] Sudre P, Hirschel BJ, Gatell JM, et al. (1996) Tuberculosis among European patients with the acquired immune deficiency syndrome. The AIDS in Europe Study Group. Tuber Lung Dis 77, 322-8. http://dx.doi.org/10.1016/S0962-8479(96)90096-9.

[29] Swaminathan S, Ramachandran R, Baskaran G, Paramasivan CN, Ramanathan U, Venkatesan P, et al (2000) Risk of development of tuberculosis in HIV-infected patients. Int J Tuberc Lung Dis 4, 83944.

[30]TB India (2013). Annual status report. Central Tuberculosis Division. Directorate General of Health Services, Ministry of Health and Family Welfare. Government of India.

[31]Wares F, Balasubramanian R, Mohan A, Sharma SK (2005). Extrapulmonary Tuberculosis: Management and Control. In: Agarwal SP, Chauhan LS, editors. Tuberculosis control in India. New Delhi: Ministry of Health and Family Welfare 95-114. 